\title{
Effect of hypertonic saline on mucociliary clearance and clinical outcomes in chronic bronchitis
}

\author{
William D. Bennett (10 1,2,4, Ashley G. Henderson ${ }^{1,4}$, Agathe Ceppe ${ }^{1}$, \\ Kirby L. Zeman ${ }^{2}$, Jihong Wu², Christine Gladman ${ }^{3}$, Fred Fuller ${ }^{1}$, \\ Stephen Gazda ${ }^{1}$, Brian Button ${ }^{1}$, Richard C. Boucher ${ }^{1}$ and Scott H. Donaldson ${ }^{1}$
}

Affiliations: ${ }^{1}$ Pulmonary and Critical Care Medicine, Dept of Medicine, University of North Carolina at Chapel Hill, Chapel Hill, NC, USA. ${ }^{2}$ Center for Environmental Medicine, Asthma and Lung Biology, University of North Carolina at Chapel Hill, Chapel Hill, NC, USA. ${ }^{3}$ Dept of Medicine, University of North Carolina at Chapel Hill, Chapel Hill, NC, USA. ${ }^{4}$ These authors contributed equally.

Correspondence: William D. Bennett, 104 Mason Farm Road, CB \#7310, Center for Environmental Medicine, Asthma and Lung Biology, University of North Carolina at Chapel Hill, Chapel Hill, NC 27599, USA.

E-mail: William_Bennettamed.unc.edu

\section{ABSTRACT}

Background: Mucus dehydration and impaired mucus clearance are common features of cystic fibrosis (CF) and chronic obstructive pulmonary disease (COPD). In CF, inhaled hypertonic saline (HS) improves lung function and produces sustained increases in mucociliary clearance (MCC). We hypothesised that administration of $\mathrm{HS}(7 \% \mathrm{NaCl})$ twice daily for 2 weeks would improve clinical outcomes and produce sustained increases in MCC in COPD subjects with a chronic bronchitis (CB) phenotype.

Methods: Twenty-two CB subjects completed a double-blinded, crossover study comparing inhaled HS to a hypotonic control solution $(0.12 \%$ saline $)$ administered via nebuliser twice daily for 2 weeks. Treatment order was randomised. During each treatment period, symptoms and spirometry were measured. MCC was measured at baseline, shortly after initial study agent administration, and approximately $12 \mathrm{~h}$ after the final dose.

Results: HS was safe and well tolerated but overall produced no significant improvements in spirometry or patient-reported outcomes. CB subjects had slower baseline MCC than healthy subjects. The MCC rates over $60 \mathrm{~min}$ (Ave60Clr) in CB subjects following 2 weeks of HS were not different from $0.12 \%$ saline but were slower than baseline (Ave60Clr was $9.1 \pm 6.3 \%$ at baseline versus $5.3 \pm 6.9 \%$ after HS; $\mathrm{p}<0.05$ ). Subgroup analyses determined that subjects with residual baseline central lung clearance (14 subjects) had improved spirometry and symptoms following treatment with HS, but not $0.12 \%$ saline, treatment.

Conclusions: Inhaled HS appeared to be safe in a general CB population. A specific phenotypic subgroup may benefit from HS but requires additional study.

@ERSpublications

2-week HS treatment in CB does not lead to overall improvement in baseline mucociliary clearance. However, a subgroup of patients with residual, noncough-induced central airway clearance does show improvement in both spirometry and symptoms. https://bit.ly/36ji6Vn

Cite this article as: Bennett WD, Henderson AG, Ceppe A, et al. Effect of hypertonic saline on mucociliary clearance and clinical outcomes in chronic bronchitis. ERJ Open Res 2020; 6: 00269-2020 [https://doi.org/10.1183/23120541.00269-2020].

This article has supplementary material available from openres.ersjournals.com

This study is registered at www.ClinicalTrials.gov with identifier number NCT01792271. We will share individual participant data that underlie the results reported in this article after deidentification (text, tables, figures and appendices). The study protocol, statistical analysis plan and analytic code will also be made available. They will be provided to anyone who wishes to access the data for any purpose beginning 3 months and ending 5 years following article publication. Requests for data should be directed to either Scott H. Donaldson (scott_donaldson@med.unc.edu) or William D. Bennett (william_bennett@med.unc.edu).

Received: 12 May 2020 | Accepted: 18 May 2020

Copyright $\odot$ ERS 2020. This article is open access and distributed under the terms of the Creative Commons Attribution Non-Commercial Licence 4.0. 


\section{Introduction}

Chronic obstructive pulmonary disease (COPD) with chronic bronchitis (CB), primarily caused by cigarette smoking, is characterised by cough, and sputum production, with or without airflow obstruction [1]. Mucociliary clearance (MCC) rates are reduced in $\mathrm{CB}$ [2-4] in association with reduced lung function [5] and increased tobacco exposure [2, 6]. As MCC declines, $\mathrm{CB}$ patients are predisposed to disease exacerbations. To date, mucolytic therapies designed to improve MCC and symptoms in $\mathrm{CB}$ have generally proven ineffective [7].

Patients with cystic fibrosis (CF) also exhibit impaired MCC from airway surface liquid depletion and mucus hyper-concentration [8]. Consequently, inhaled hyperosmotic solutions are routinely used to hydrate mucus and accelerate MCC [9-11]. Both single [12] and repetitive [11] dosing of inhaled 7\% hypertonic saline (HS) have prolonged effects on MCC in CF and likely mediated the reduction in pulmonary exacerbation rate in a long-term study of HS in CF [13].

We recently reported that $\mathrm{CB}$ secretions are moderately hyper-concentrated, with increased sputum \% solids and total mucin concentrations $[5,14]$, and that central lung MCC negatively correlated with lower airway mucus sample concentrations [5]. Although the magnitude of hyper-concentration in CB $(\sim 3.5 \%)$ is substantially less than in CF ( $\sim 8 \%$ solids) $[15,16]$ we hypothesised that chronic HS treatment might also benefit CB patients. HS has been shown to acutely stimulate MCC in CB subjects [17, 18], but the duration of this effect and its impact on clinical outcomes have not been assessed. We, therefore, performed a study to determine the effects of HS on MCC, lung function, and symptoms in this population. Comparative baseline MCC measurements in healthy, nonsmoking adults were used to define MCC defects observed in CB subjects.

\section{Methods}

\section{Patient recruitment}

Inclusion criteria included COPD with CB symptoms [19], age 40-80 years, airways obstruction (forced expiratory volume in $1 \mathrm{~s}\left(\mathrm{FEV}_{1}\right) /$ forced vital capacity $\left.(\mathrm{FVC})<0.70\right)$ and $\mathrm{FEV}_{1} 35-80 \%$ of predicted. Both former and active smokers ( $\geqslant 10$ pack-years) were included. Significant exclusions included a clinical history of asthma or bronchodilator reversibility at screening; daytime oxygen or chronic prednisone ( $>10 \mathrm{mg} \cdot \mathrm{d}^{-1}$ or equivalent corticosteroid dose) requirement; and recent changes in respiratory medications or health status within 4 weeks prior to study enrolment.

Thirty-three healthy, nonsmoking control subjects underwent a single MCC scan. These data were recently reported but are provided for comparison purposes [20,21].

\section{Study design}

CB subjects meeting enrolment criteria were randomised to a treatment sequence in a double-blinded, crossover study. Each treatment period was 2 weeks in duration, with an intervening 2-4-week washout period. Randomisation was performed by the investigational pharmacy in a combined block of four and block of six pattern.

Study agents included inhaled $\mathrm{HS}(7 \% \mathrm{NaCl} \times 4 \mathrm{~mL})$ and $\mathrm{HS}(0.12 \% \mathrm{NaCl} \times 4 \mathrm{~mL})$ delivered via a PARI LC Star nebuliser with Pari PRONEB Ultra Compressor twice daily (figure 1). The control hypotonic solution was selected to provide a low osmotic load that was less likely to acutely enhance MCC than isotonic saline [22], while also avoiding the deleterious effects (e.g. bronchospasm) that may occur after inhalation of distilled water [23]. MCC and cough clearance (CC) were measured via gamma scintigraphy at: 1) baseline; 2) 20-25 min after the first dose of the assigned study treatment; and 3) 12 h after the last dose of study treatment (figure 1). A dose of albuterol (four puffs of $90 \mu \mathrm{g}$ each via metered dose inhaler with spacer) was administered during spirometry, approximately $60 \mathrm{~min}$ before each MCC/CC study. Patients were instructed to use albuterol prior to HS or control treatment at home.

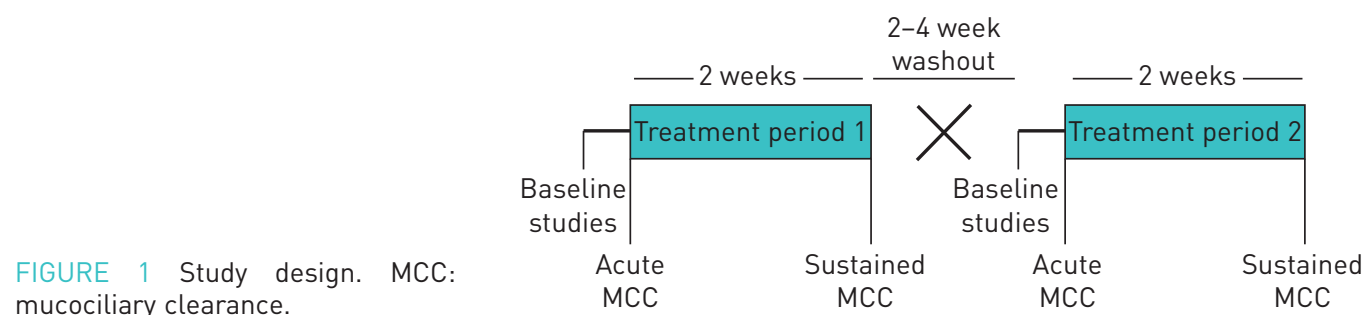




\section{Safety/tolerability}

The acute tolerability of each study treatment was assessed by monitoring symptoms, physical exam, pulse oximetry, and spirometry (pre-dose and $2 \mathrm{~h}$ post-dose) around the first administered dose. Adverse events were noted at all visits and a phone contact during each treatment. Adverse event severity was graded using the Common Terminology Criteria for Adverse Events version 3.0, with grade 3 or higher events considered as severe.

\section{Clinical end-points}

Spirometry was performed according to American Thoracic Society standards [24] before administration of study medications at each visit. The St. George's respiratory questionnaire for COPD (SGRQ-C) [25] and cough and sputum questionnaire (CASA-Q) [26] assessed patient-reported outcomes. A 6-min walk test was completed before and after each 2-week treatment period.

\section{Mucociliary/cough clearance}

$\mathrm{A} \mathrm{Co}^{57}$ transmission scan was performed prior to radioaerosol inhalation to outline lung margins and generate the central $(\mathrm{C})$ and peripheral $(\mathrm{P})$ regions of interest (ROIs) $[27,28]$ used to assess initial particle deposition $(\mathrm{C} / \mathrm{P})$ and subsequent clearance.

Radiolabelled (Tc99m-sulfur colloid) aerosols were inhaled with a SILP (slow inhalation $\left(80 \mathrm{~mL} \cdot \mathrm{s}^{-1}\right)$, large particle $(9.5 \mu \mathrm{m}$ mass median aerodynamic diameter) $)$ methodology [20, 21]. To adjust for the smaller ventilated volume in $\mathrm{CB}$ and to reduce dyspnoea during this very slow inspiratory manoeuvre, a 6-s inhalation time was used in $\mathrm{CB}$ subjects, rather than the 10-s inhalation previously used in healthy subjects $[20,21]$. After tracer inhalation, serial 2-min particle retention images were acquired via gamma scintigraphy. Subjects were asked to refrain from coughing until the 60-90 min imaging interval, when 20 voluntarily coughs were performed during each 10-min interval. Subjects returned the following day to assess 24 -h tracer clearance $( \pm 4 \mathrm{~h})(24 \mathrm{~h} \mathrm{Clr})$.

Serial measurements of radioactive counts (decay and background corrected) over time in the right lung characterised whole, central, and peripheral lung clearances as a fraction of initial deposited counts. The average rate of clearance through $60 \mathrm{~min}$ (AveClr60) in the whole right lung was calculated using clearance values at 10-min intervals [21]. Cough-dominated clearance (60-90 min; Ave60-90Clr) and regional clearance rates were similarly calculated.

Baseline MCC studies in $\mathrm{CB}$ subjects were compared to those recently performed in healthy, never-smoking adults with normal lung function $(n=33)[20,21]$. The identical SILP deposition method was utilised in both studies, except for the above-mentioned differences in inhalation times. Ave60Clr for MCC was used as the primary outcome for this comparison, as controlled coughing during the 60-90-min period was not included in the healthy adult study.

\section{Sputum percentage solids}

Spontaneous sputum samples were collected prior to each MCC measurement and stored frozen. Wet and dry weights were used to calculate sputum percentage solids content [29].

\section{Statistics}

The prespecified primary study outcome was the change in whole lung AveClr60 between baseline and end of treatment. Secondary outcomes included changes in spirometry, patient-reported outcomes, and other MCC outcomes. From previous repeated MCC measures in CB subjects, 24 subjects were determined to sufficiently provide $80 \%$ power to detect a $3.75 \%$ absolute change in AveClr60 with $\alpha$ set at 0.05 using a paired, two-sided t-test.

Data were analysed using a repeated measure ANOVA per treatment using subjects as a random effect, with visit and treatment period as fixed effects. Comparison between treatments were analysed with paired t-tests if visit was a significant effect. The relationship between specific outcomes was determined by Pearson's correlation. Comparisons between $\mathrm{CB}$ and healthy subjects were made with independent t-tests. Subgroup comparisons were analysed with paired t-tests. A p-value $<0.05$ was considered significant. All statistical analyses were conducted utilising SAS version 9.4 and JMP Pro 14 (SAS, Cary, NC, USA) statistical software.

\section{Study approval}

The study was approved by the University of North Carolina Institutional Review Board, and subjects provided written informed consent. The study was registered at Clinical Trials.gov (NCT01792271). 


\begin{tabular}{|c|c|c|}
\hline & $\begin{array}{l}\text { Chronic bronchitis } \\
\qquad(n=22)\end{array}$ & $\begin{array}{l}\text { Healthy volunteers } \\
\qquad(\mathrm{n}=33 \text { ) }\end{array}$ \\
\hline Age years & $62.2 \pm 9.7$ & $26.3 \pm 5.9$ \\
\hline Female & $13(59 \%)$ & $10(30 \%)$ \\
\hline \multicolumn{3}{|l|}{ Race } \\
\hline Black & $4(18 \%)$ & $6(18 \%)$ \\
\hline White & $18(82 \%)$ & $27(82 \%)$ \\
\hline Current smokers & $57 \%$ & 0 \\
\hline FEV $1 \%$ pred & $57 \pm 12$ & $99.5 \pm 12.7$ \\
\hline \multicolumn{3}{|l|}{ GOLD classification } \\
\hline GOLD II & $17(77 \%)$ & \\
\hline GOLD III & $5(23 \%)$ & \\
\hline $\begin{array}{l}\text { Cough and phlegm produced at least several days a } \\
\text { week (by SGRQ-C) }\end{array}$ & $18(82 \%)$ & N/A \\
\hline \multicolumn{3}{|l|}{ Concomitant medications } \\
\hline Long-acting beta agonist & $12(55 \%)$ & \\
\hline Long-acting antimuscarinic & $11(50 \%)$ & \\
\hline Inhaled corticosteroid & $14(64 \%)$ & \\
\hline
\end{tabular}

\section{Results}

\section{Subject disposition and demographics}

Twenty-five subjects were enrolled at a single academic centre between March 2013 and March 2016 (Supplement figure 1). The study was stopped after meeting enrolment goals. Twenty-four subjects received more than one dose of study drug and 22 completed the study. One subject withdrew consent due to fatigue related to spirometry. Two subjects withdrew early; one due to chest tightness and oxygen desaturation during the HS test dose, as described below, and one was lost to follow-up due to incarceration.

Demographics for the evaluable $\mathrm{CB}(\mathrm{n}=22)$ and healthy study populations are shown in table 1 . The majority of $\mathrm{CB}$ subjects were classified as Gold II by Global Initiative for Chronic Obstructive Lung Disease COPD criteria, were current smokers, regularly produced sputum, and exhibited moderate mucus hyper-concentration. The majority of subjects used one or more controller medications (long-acting beta agonist, long-acting anti-muscarinic, or inhaled corticosteroid); $32 \%$ regularly used no controller medication.

\section{Safety assessments}

No significant $\mathrm{FEV}_{1}$ changes were observed $2 \mathrm{~h}$ after the first dose of either study treatment (table 2) and no individual subject exceeded the predefined stopping criteria of a $20 \%$ relative decrease in $\mathrm{FEV}_{1}$. One subject reported chest tightness and experienced oxygen desaturation after the initial HS dose, which quickly reversed after two puffs of albuterol, and was withdrawn from the study. No serious or severe

\section{TABLE 2 Post-bronchodilator $\mathrm{FEV}_{1}$ and $\mathrm{FEF}_{25-75} \%$ predicted}

\begin{tabular}{|c|c|c|c|c|c|}
\hline & & \multirow[t]{2}{*}{ Baseline } & \multicolumn{2}{|c|}{ Acute $^{\#}$} & \multirow[t]{2}{*}{2 weeks (sustained") } \\
\hline & & & Pre-treatment & Post-treatment & \\
\hline \multirow[t]{2}{*}{$0.12 \%$ saline } & $\mathrm{FEV}_{1}$ & $57.9 \pm 12.6$ & $59.2 \pm 12.3$ & $57.6 \pm 13.6$ & $59.4 \pm 13.3$ \\
\hline & $\mathrm{FEF}_{25-75}$ & $31.6 \pm 13.7$ & $33.2 \pm 13.0$ & $31.7 \pm 13.6$ & $34.5 \pm 16.2$ \\
\hline \multirow[t]{2}{*}{$7 \%$ saline } & $\mathrm{FEV}_{1}$ & $58.9 \pm 13.2$ & $58.0 \pm 12.6$ & $58.0 \pm 12.5$ & $59.2 \pm 12.9$ \\
\hline & $\mathrm{FEF}_{25-75}$ & $33.6 \pm 14.9$ & $34.6 \pm 17.5$ & $31.6 \pm 16.5$ & $33.5 \pm 15.1$ \\
\hline
\end{tabular}

Data are presented as mean $\pm \mathrm{SD}$. $\mathrm{FEV}_{1}$ : forced expiratory volume in $1 \mathrm{~s} ; \mathrm{FEF}_{25-75}$ : forced expiratory flow at $25-75 \%$ of forced vital capacity. " : acute values were measured immediately before and $2 \mathrm{~h}$ after first dose of study treatment; ${ }^{9}$ : sustained values measured $\sim 12 \mathrm{~h}$ after final dose of 2 -week treatment period. 


\begin{tabular}{|c|c|c|c|c|}
\hline & MCC (Ave60) & CC (Ave60-90) & $\mathrm{C} / \mathrm{P}$ & $24 \mathrm{~h} \mathrm{Clr}$ \\
\hline Healthy adult baseline $n=33$ & $14.3 \pm 7.2$ & & $2.30 \pm 0.36$ & $48 \pm 9$ \\
\hline CB period 1 baseline $n=22$ & $8.4 \pm 8.2^{\#}$ & & $2.42 \pm 1.10$ & $50 \pm 16$ \\
\hline \multicolumn{5}{|l|}{ СВ HS (7\% saline) } \\
\hline Baseline & $9.1 \pm 6.3$ & $11.7 \pm 11.5$ & $2.35 \pm 0.90$ & $51 \pm 15$ \\
\hline Acute & $9.6 \pm 9.7$ & $10.9 \pm 10.8$ & $2.23 \pm 0.66$ & $51 \pm 17$ \\
\hline 2 weeks & $5.3 \pm 6.9^{\text {ๆ }}$ & $9.6 \pm 10.0$ & $2.50 \pm 0.98$ & $52 \pm 13$ \\
\hline \multicolumn{5}{|l|}{ Control $(0.12 \%$ saline $)$} \\
\hline Baseline & $9.0 \pm 10.6$ & $9.4 \pm 9.9$ & $2.32 \pm 1.05$ & $49 \pm 15$ \\
\hline Acute & $7.7 \pm 9.4$ & $8.7 \pm 9.4$ & $2.35 \pm 0.94$ & $51 \pm 13$ \\
\hline 2 weeks & $6.2 \pm 5.7$ & $8.8 \pm 2.7$ & $2.48 \pm 0.88$ & $50 \pm 16$ \\
\hline \multicolumn{5}{|c|}{$\begin{array}{l}\text { Data are presented as mean } \pm \mathrm{SD} \text {. MCC: mucociliary clearance; } \mathrm{CC} \text { : cough clearance; Ave } 60 \mathrm{Clr} \text { : average rate } \\
\text { of clearance through } 60 \mathrm{~min} ; \mathrm{C} / \mathrm{P}: \text { central/peripheral; } 24 \mathrm{~h} \mathrm{Clr}: 24-\mathrm{h} \text { tracer clearance; CB: chronic } \\
\text { bronchitis; HS: hypertonic saline. \#: } \mathrm{p}<0.01 \text { compared to healthy adult baseline by t-test.; } \text { १: } p<0.05 \\
\text { compared to CB HS baseline. }\end{array}$} \\
\hline
\end{tabular}

adverse events were reported. One pulmonary exacerbation occurred during the washout period; the patient resumed participation after returning to their clinical baseline.

\section{Clinical end-points}

No changes in spirometry values were observed after 2 weeks of either study treatment (table 2). Similarly, there were no differences in 6-min walk distance (metres) (2.2 \pm 107.4 versus $-1.1 \pm 206.6$; HS and $0.12 \%$ saline, respectively) or change in the SGRQ-C overall score (supplementary table). The SGRQ-C symptom score subdomain exhibited a nonsignificant improvement from baseline after HS $(-5.0 \pm 13.9 ; \mathrm{p}=0.10)$, but not $0.12 \%$ saline $(1.6 \pm 15.9 ; \mathrm{p}=0.65)$, which exceeded the accepted minimal clinically important difference value of 4 [30]. No effects of HS or control solutions were observed on other SGRQ subdomain or CASA-Q scores (supplementary table).

\section{Analysis of regional MCC in CB and healthy subjects}

Comparison of baseline MCC measurements in CB subjects at the beginning of periods 1 and 2 revealed moderate intra-subject correlation (mean whole lung AveClr60\% (SD): $8.4 \pm 8.2$ versus 9.8 \pm 9.2 , respectively; $\mathrm{r}=0.55, \mathrm{p}<0.01)$. No carryover effects were detected.

Baseline whole and central lung MCC were significantly lower in CB subjects when compared to healthy nonsmoking adults (tables 3 and 4). In contrast, peripheral lung MCC was not different (table 4). Regional deposition ( $\mathrm{C} / \mathrm{P}$ ratio) was not different between the groups and, thus, did not confound comparisons of whole lung Ave60Clr.

To further investigate the slow $\mathrm{C}$ region clearance in $\mathrm{CB}$, we examined the distribution of baseline Central Lung AveClr60\% values in CB (pre-HS baseline) and healthy subjects (figure 2). These distributions revealed an overall slowing of clearance and a distinct subset of CB subjects with absent $\mathrm{C}$ region clearance ( $\mathrm{n}=8$ in the

\section{TABLE 4 Regional MCC (Ave60Clr)}

\section{Central (\%)}

Healthy adult baseline $n=33$

CB period 1 baseline $\mathrm{n}=22$

CB HS (7\% saline)

Baseline

2 weeks

CB control $(0.12 \%$ saline)

Baseline

2 weeks

$\begin{array}{cc}15.9(10.5) & 12.6(7.2) \\ 4.7(11.6)^{\#} & 11.2(9.3) \\ & \\ 5.7(10.4) & 12.3(7.0) \\ 1.5(10.0) & 8.4(9.0) \\ 4.1(15.7) & 12.6(11.3) \\ 2.7(9.6) & 9.3(7.2)\end{array}$

Data are presented as mean \pm SD. MCC: mucociliary clearance; Ave60Clr: average rate of clearance through $60 \mathrm{~min}$; CB: chronic bronchitis; HS: hypertonic saline. ${ }^{\#}$ : $p<0.001$ compared to healthy adults by t-test. 


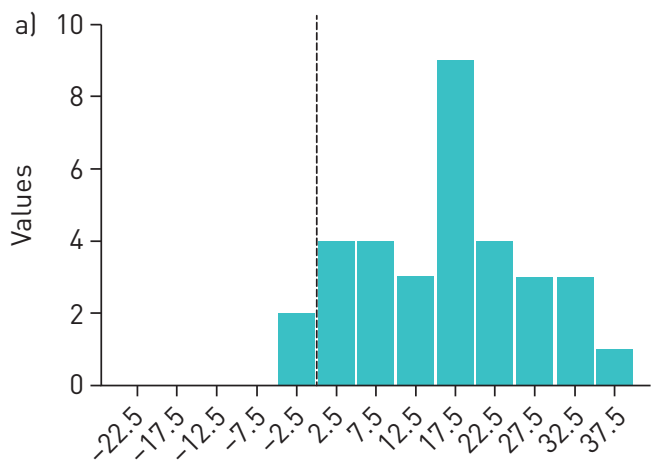

Central Lung Ave60

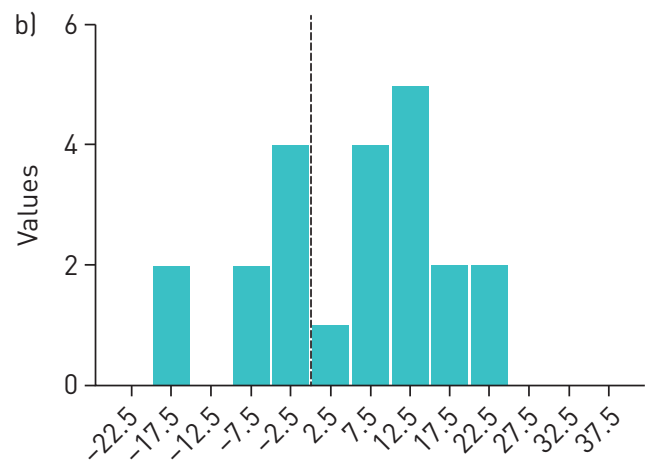

Central Lung Ave60

FIGURE 2 Distribution of Central Lung average clearance through $60 \mathrm{~min}$ (Ave60Clr) (\%) values in a) healthy and b) chronic bronchitis (CB) subjects. Dotted line indicates zero net clearance over $60 \mathrm{~min}$.

pre-HS arm) with a net accumulation of particles in the $\mathrm{C}$ region during the 60 -min period before voluntary coughs. As demonstrated by one $\mathrm{CB}$ subject, activity initially deposited in the trachea flowed retrograde into the right lung before eventually being expelled by cough (see supplementary video). CB cohorts segregated by baseline "absent" versus "residual" C region clearance were evaluated in post hoc analyses.

\section{Effect of HS on mucociliary/cough clearance in CB}

In $\mathrm{CB}$ subjects, neither $7 \%$ nor $0.12 \%$ saline inhaled $20-25 \mathrm{~min}$ before radioaerosol administration had an effect on whole lung MCC or CC (figure 3 and table 3). Indices of regional deposition (C/P and $24 \mathrm{~h} \mathrm{Clr}$ ) were unchanged post-treatment (table 3), indicating that altered particle deposition probably did not account for the absence of MCC effects. Concomitant use of COPD controller medications also had no effect on this result.

After 2 weeks of twice-daily HS treatment, a significant slowing of whole lung MCC (Ave60Clr) from baseline (figure $3 \mathrm{a}$ and table 3 ) was observed $12 \mathrm{~h}$ after the last dose of HS. No slowing was observed during the cough interval (Ave60-90Clr), suggesting that cilia, and not cough-driven clearance was reduced by repeated HS treatment. A similar, but nonsignificant pattern of slowed whole lung MCC from baseline was observed after 2 weeks of $0.12 \%$ saline use (figure $3 \mathrm{~b}$ and table 3 ). Particle deposition indices (C/P and 24Clr; table 3 ) were well matched across all visits and groups, reducing the risk that altered radioaerosol deposition confounded clearance measurements. The slowing of MCC after HS was driven by subjects not using COPD controller medications (mean difference: $-9.9 \pm 2.4 \%$ ) versus those using these concomitant treatments (mean difference: $-1.1 \pm 1.6 \%$; $=0.006$ ).

Post hoc subgroup analyses

The striking abnormality in $\mathrm{C}$ region clearance in $\mathrm{CB}$ subjects (figure 2) is reminiscent of observations made in patients with primary ciliary dyskinesia [31]. We, therefore, hypothesised that ciliary dysfunction

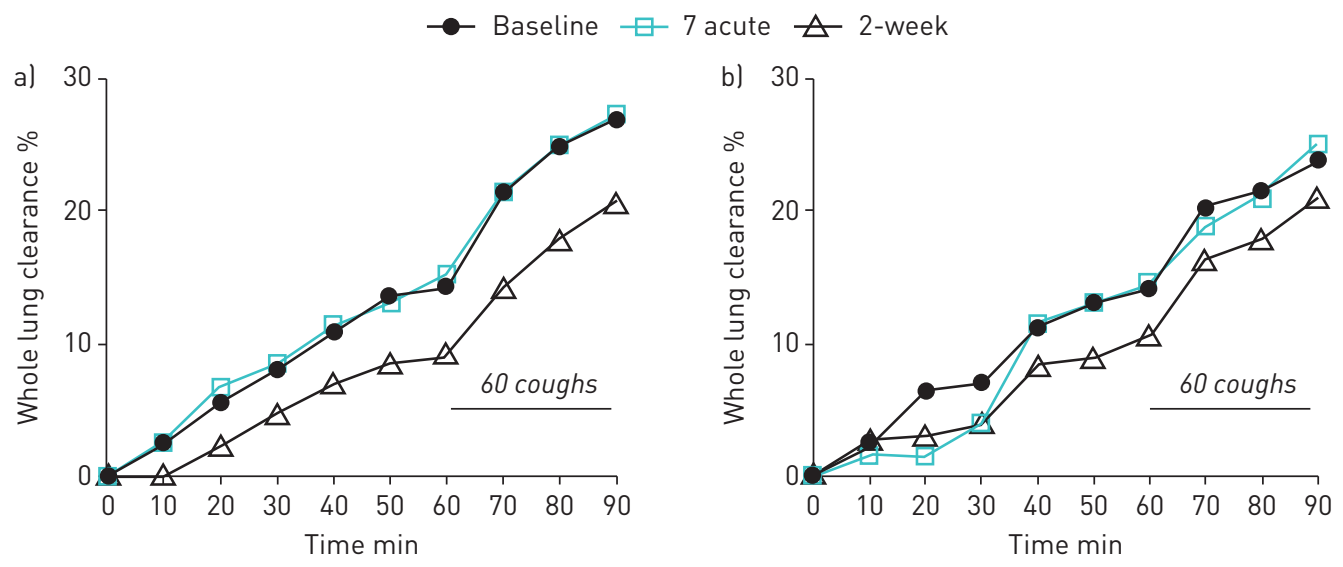

FIGURE 3 a) Mean whole lung mucus clearance for inhaled 7\% hypertonic saline. b) Mean whole lung mucus clearance for inhaled $0.12 \%$ saline. 
may also contribute to the observed MCC defect. We further hypothesised that the clinical response to HS could depend upon whether ciliary function remained intact in CB subjects.

Indeed, CB subjects with residual (Ave60>0; n=14) C region clearance experienced small but significant improvements from baseline in $\mathrm{FEV}_{1} \%$ predicted $(+2.4 \pm 4.0 \% ; \mathrm{p}=0.04)$ and SGRQ symptom scores $(-8.2 \pm 13.1 ; \mathrm{p}=0.04)$. No improvement in $\mathrm{FEV}_{1}(-2.6 \pm 5.8 \% ; \mathrm{p}=0.24)$ or symptoms $(+0.4 \pm 14.3 ; \mathrm{p}=0.94)$ were observed in the "absent clearance" group (AveClr60<0; $n=8$ ), and no improvements were seen in either subgroup with $0.12 \%$ saline treatment. The effects of HS on spirometry and SGRQ were linearly related to baseline C MCC (supplementary figure 2). Of note, improvements in clinical end-points in the "residual clearance" group were not mirrored by sustained improvement in MCC. In fact, significant slowing of MCC was observed with HS treatment in this group, as was observed in the overall group, and as previously reported in healthy volunteers [21]. Smoking status at the time of enrolment was not associated with the $\mathrm{C}$ region MCC phenotype and did not predict treatment responses. Concomitant use of COPD controller medications did not impact the observed effect of $\mathrm{HS}$ on $\mathrm{FEV}_{1}$ and symptom score.

\section{Discussion}

Aerosolised HS appeared to be generally safe in CB subjects with moderate obstruction. Only one subject demonstrated acute intolerance to $\mathrm{HS}$ but mean $\mathrm{FEV}_{1}$ measured $2 \mathrm{~h}$ after the first dose was not reduced by HS. However, no sustained improvements in spirometry, 6-min walk distance, or patient-reported outcomes were noted, although a trend toward an improved SGRQ symptom score, which exceeded the minimal clinically important difference value, was observed after 2 weeks of HS.

The absence of an acute MCC effect 20-25 min after inhaling HS is consistent with our previous observations in healthy volunteers [21], but contrasts with observations made in CF adults [12]. This probably reflects a short duration of HS action (i.e. $<20-25 \mathrm{~min}$ ) on MCC in CB. In previous studies that did show an acute stimulation of MCC with HS in CB, HS was administered either immediately before the radiotracer ( $<5 \mathrm{~min})$ [18] or afterwards [17], allowing capture of an immediate HS effect on MCC/CC.

The paradoxical slowing of MCC following 2 weeks HS administration in CB subjects was unexpected. We previously observed slowing of MCC $4 \mathrm{~h}$ after a single administration of inhaled HS in healthy adults [21], an observation speculated to reflect depletion of mobile mucus on airway surfaces by HS. This postulated mechanism rested on studies by IRAVANI and VAN As [32], who observed that mobile mucus was normally transported as sparse mucus islands, rather than as a continuous mucus sheet. This model predicts that if the density of mobile mucus islands on airway surfaces was reduced by a preceding stimulus for clearance (e.g. HS), clearance of newly deposited tracer molecules would be slowed by increased deposition onto mucus depleted airways. The sustained enhancement of MCC by HS observed in CF [11] may reflect the presence of copious mucus on CF airway surfaces, providing a "reservoir" of mucus to mediate the prolonged acceleration of tracer particles trapped in HS-rehydrated mucus [10]. The failure to observe such an effect in COPD may reflect a lesser mucus burden. The clinical significance of MCC slowing after $\mathrm{HS}$ in $\mathrm{CB}$ is unknown, as is the mechanism explaining why this reduction was prevented by use of COPD controller medications.

Comparisons of the basal MCC patterns in $\mathrm{CB}$ and healthy subjects yielded insights into the multifactorial processes that impair MCC in COPD. Our observation of a striking central airway clearance defect (table 4) and retrograde clearance from the trachea to central airways (supplementary video) suggested a large airway ciliary abnormality. Preferential slowing of central airway clearance, reduced tracheal mucus velocity, and retrograde mucus flow in CB have also been reported previously [5, 33-35]. A ciliary defect in $\mathrm{CB}$ is further supported by reports of reduced numbers and dysfunctional cilia in human subjects with COPD with chronic cigarette smoke exposure [36-39], as well as animal data from IrAVANI and VAN As [32], who demonstrated dyssynchronous ciliary beating and disorganised MCC in a rat model of CB. Ciliary dysfunction, in addition to mucus hyper-concentration may, therefore, be a major contributor to abnormal central airways MCC in COPD.

COPD has been shown to involve the small airways via histopathology, imaging, and functional assessments [40-42]. In contrast, our data suggests that MCC is preserved in the peripheral lung ROI, whereas significant clearance defects are seen centrally. It should be emphasised, however, that MCC is only reported from airways where aerosolised radiolabelled tracer deposits. Our peripheral MCC rates, therefore, probably reflect clearance from relatively "healthy" versus more obstructed, peripheral airways. A combination of "lost" small airways with reduced large airway clearance may together explain the clinical findings of airflow obstruction, dyspnoea, exercise limitation, and propensity for infectious exacerbations.

Finally, we investigated whether there were differential responses to inhaled HS based on MCC patterns or other clinical features. Indeed, subjects with residual central airway mucus clearance exhibited significant improvements both in lung function and symptoms after HS. We postulate that HS improved the 
rheologic properties of mucus via rehydration, but this was only beneficial when intact ciliary function was present. Collectively, these findings suggest that specific CB patient populations, identifiable by baseline MCC measurements, might benefit from inhaled HS.

We acknowledge a few limitations to this clinical study. First, our sequential treatment periods were limited to 2 weeks duration. This design element was made to reduce variability that may confound longer crossover studies, and to match the treatment duration utilised in our previous HS trial in CF subjects [11]. It is possible that a longer duration trial would have substantiated the positive trends in symptom scores and lung function seen here in a subgroup, and allowed for assessment of exacerbations as an additional clinical end-point. Next, the small sample size reduces our ability to confidently assess the surprising improvements in lung function and symptoms after HS in a subgroup with preserved central ROI clearance at baseline, despite the absence of clinical benefits in the overall population. Finally, substantial lack of sputum data also prevented us from determining whether changes in sputum hydration occurred or predicted MCC or clinical changes.

\section{Conclusion}

In summary, MCC rates were significantly reduced in the central airways of CB subjects. Although HS use appeared to be safe, it was not associated with improved spirometry, symptoms, or MCC in the overall $\mathrm{CB}$ cohort. MCC studies, however, identified a subset of CB subjects with preserved ciliary function that had improved spirometry and symptoms following 2 weeks of HS administration. The identification of biomarkers that reflect ciliary dysfunction may allow personalised therapy for subjects with the highly heterogeneous COPD syndrome.

Author contributions: The study was conceptualised and designed by S.H. Donaldson, A.G. Henderson, R.C. Boucher, and W.D. Bennett. Data were acquired by A.G. Henderson, W.D. Bennett, K.L. Zeman, J. Wu, F. Fuller, S. Gazda, B. Button, and S.H. Donaldson. Data were analysed and interpreted by S.H. Donaldson, A. Ceppe, W.D. Bennett, A.G. Henderson, C. Gladman, and R.C. Boucher. The manuscript was drafted by W.D. Bennett and S.H. Donaldson, and revised by W.D. Bennett, S.H. Donaldson, A. Ceppe, R.C. Boucher, and A.G. Henderson.

Conflict of interest: W.D. Bennett reports grants from the NHLBI (NIH) during the conduct of the study. A.G. Henderson reports grants from National Institutes of Health during the conduct of the study. A. Ceppe reports grants from NHLBI (NIH) during the conduct of the study. K.L. Zeman reports grants from the NHLBI (NIH) during the conduct of the study. J. Wu reports grants from the NHLBI (NIH) during the conduct of the study. C. Gladman reports grants from the NHLBI (NIH), during the conduct of the study. F. Fuller reports grants from the NHLBI (NIH) during the conduct of the study. S. Gazda reports grants from the NHLBI (NIH) during the conduct of the study. B. Button reports grants from the NHLBI (NIH) during the conduct of the study. R.C. Boucher reports grants from the NHLBI (NIH) during the conduct of the study. Parion Sciences is a privately held UNC spin-out company focused on developing therapies for CF. He is chairman of the Board of Parion, has equity in it and has received monetary compensation as Board Chair. S.H. Donaldson reports grants from the NHLBI (NIH) during the conduct of the study.

Support statement: This study was supported by National Heart, Lung, and Blood Institute grant NHLBI/NIH 1 P01 HL 108808. Funding information for this article has been deposited with the Crossref Funder Registry.

\section{References}

1 Drummond MB, Buist AS, Crapo JD, et al. Chronic obstructive pulmonary disease: NHLBI Workshop on the Primary Prevention of Chronic Lung Diseases. Ann Am Thorac Soc 2014; 11 Suppl 3: S154-160.

2 Vastag E, Matthys $\mathrm{H}$, Kohler D, et al. Mucociliary clearance and airways obstruction in smokers, ex-smokers and normal subjects who never smoked. Eur J Respir Dis Suppl 1985; 139: 93-100.

3 Mossberg B, Strandberg K, Philipson K, et al. Tracheobronchial clearance and beta-adrenoceptor stimulation in patients with chronic bronchitis. Scand J Respir Dis 1976; 57: 281-289.

4 Camner P, Mossberg B, Philipson K. Tracheobronchial clearance and chronic obstructive lung disease. Scand J Respir Dis 1973; 54: 272-281.

5 Anderson WH, Coakley RD, Button B, et al. The relationship of mucus concentration (hydration) to mucus osmotic pressure and transport in chronic bronchitis. Am J Respir Crit Care Med 2015; 192: 182-190.

6 Goodman RM, Yergin BM, Landa JF, et al. Relationship of smoking history and pulmonary function tests to tracheal mucous velocity in nonsmokers, young smokers, ex-smokers, and patients with chronic bronchitis. Am Rev Respir Dis 1978; 117: 205-214.

7 Tarrant BJ, Le Maitre C, Romero L, et al. Mucoactive agents for chronic, non-cystic fibrosis lung disease: A systematic review and meta-analysis. Respirology 2017; 22: 1084-1092.

8 Donaldson SH, Corcoran TE, Laube BL, et al. Mucociliary clearance as an outcome measure for cystic fibrosis clinical research. Proc Am Thorac Soc 2007; 4: 399-405.

9 Robinson M, Daviskas E, Eberl S, et al. The effect of inhaled mannitol on bronchial mucus clearance in cystic fibrosis patients: a pilot study. Eur Respir J 1999; 14: 678-685.

10 Goralski JL, Wu D, Thelin WR, et al. The in vitro effect of nebulised hypertonic saline on human bronchial epithelium. Eur Respir J 2018; 51: 1702652.

11 Donaldson SH, Bennett WD, Zeman KL, et al. Mucus clearance and lung function in cystic fibrosis with hypertonic saline. N Engl J Med 2006; 354: 241-250. 
12 Trimble AT, Whitney Brown A, Laube BL, et al. Hypertonic saline has a prolonged effect on mucociliary clearance in adults with cystic fibrosis. J Cyst Fibros 2018; 17: 650-656.

13 Elkins MR, Robinson M, Rose BR, et al. A controlled trial of long-term inhaled hypertonic saline in patients with cystic fibrosis. N Engl J Med 2006; 354: 229-240.

14 Henderson AG, Anderson WH, Ceppe A, et al. Mucus hydration in subjects with stable chronic bronchitis: a comparison of spontaneous and induced sputum. COPD 2018; 15: 572-580.

15 Ma JT, Tang C, Kang L, et al. Cystic fibrosis sputum rheology correlates with both acute and longitudinal changes in lung function. Chest 2018; 154: 370-377.

16 Martens CJ, Inglis SK, Valentine VG, et al. Mucous solids and liquid secretion by airways: studies with normal pig, cystic fibrosis human, and non-cystic fibrosis human bronchi. Am J Physiol Lung Cell Mol Physiol 2011; 301 L236-L246.

17 Pavia D, Thomson ML, Clarke SW. Enhanced clearance of secretions from the human lung after the administration of hypertonic saline aerosol. Am Rev Respir Dis 1978; 117: 199-203.

18 Clunes LA, Davies CM, Coakley RD, et al. Cigarette smoke exposure induces CFTR internalization and insolubility, leading to airway surface liquid dehydration. FASEB J 2012; 26: 533-545.

19 Pauwels RA, Buist AS, Ma P, et al. Global strategy for the diagnosis, management, and prevention of chronic obstructive pulmonary disease: National Heart, Lung, and Blood Institute and World Health Organization Global Initiative for Chronic Obstructive Lung Disease (GOLD): executive summary. Respir Care 2001; 46: 798-825.

20 Zeman KL, Wu J, Bennett WD. Targeting aerosolized drugs to the conducting airways using very large particles and extremely slow inhalations. J Aerosol Med Pulm Drug Deliv 2010; 23: 363-369.

21 Bennett WD, Wu J, Fuller F, et al. Duration of action of hypertonic saline on mucociliary clearance in the normal lung. J Appl Physiol 2015; 118: 1483-1490.

22 Sood N, Bennett WD, Zeman K, et al. Increasing concentration of inhaled saline with or without amiloride: effect on mucociliary clearance in normal subjects. Am J Respir Crit Care Med 2003; 167: 158-163.

23 Bascom R, Bleecker ER. Bronchoconstriction induced by distilled water. Sensitivity in asthmatics and relationship to exercise-induced bronchospasm. Am Rev Respir Dis 1986; 134: 248-253.

24 Graham BL, Steenbruggen I, Miller MR, et al. An Official American Thoracic Society and European Respiratory Society technical statement. Am J Respir Crit Care Med; 2019: e70-e88.

25 Meguro M, Barley EA, Spencer S, et al. Development and validation of an improved, COPD-specific version of the St. George respiratory questionnaire. Chest 2007; 132: 456-463.

26 Crawford B, Monz B, Hohlfeld J, et al. Development and validation of a cough and sputum assessment questionnaire. RespirMed 2008; 102: 1545-1555.

27 Bennett WD, Laube BL, Corcoran T, et al. Multisite comparison of mucociliary and cough clearance measures using standardized methods. J Aerosol Med Pulm Drug Deliv 2013; 26: 157-164.

28 Zeman KL, Wu J, Donaldson SH, et al. Comparison of 133 xenon ventilation equilibrium scan (XV) and $99 \mathrm{~m}$ technetium transmission (TT) scan for use in regional lung analysis by 2D gamma scintigraphy in healthy and cystic fibrosis lungs. J Aerosol Med Pulm Drug Deliv 2013; 26: 94-100.

29 Button B, Cai LH, Ehre C, et al. A periciliary brush promotes the lung health by separating the mucus layer from airway epithelia. Science 2012; 337: 937-941.

30 Jones PW. St. George's respiratory questionnaire: MCID. COPD 2005; 2: 75-79.

31 Regnis JA, Zeman KL, Noone PG, et al. Prolonged airway retention of insoluble particles in cystic fibrosis versus primary ciliary dyskinesia. Exp Lung Res 2000; 26: 149-162.

32 Iravani J, van As A. Mucus transport in the tracheobronchial tree of normal and bronchitic rats. J Pathol 1972; 106: 81-93.

33 Smaldone GC, Foster WM, O’Riordan TG, et al. Regional impairment of mucociliary clearance in chronic obstructive pulmonary disease. Chest 1993; 103: 1390-1396.

34 Isawa T, Teshima T, Hirano T, et al. Lung clearance mechanisms in obstructive airways disease. J Nucl Med 1984; 25: $447-454$.

35 Morgan L, Pearson M, de Iongh R, et al. Scintigraphic measurement of tracheal mucus velocity in vivo. Eur Respir J 2004; 23: 518-522.

36 Auerbach O, Hammond EC, Garfinkel L. Changes in bronchial epithelium in relation to cigarette smoking, 1955-1960 vs. 1970-1977. N Engl J Med 1979; 300: 381-385.

37 Verra F, Escudier E, Lebargy F, et al. Ciliary abnormalities in bronchial epithelium of smokers, ex-smokers, and nonsmokers. Am J Respir Crit Care Med 1995; 151: 630-634.

38 Leopold PL, O’Mahony MJ, Lian XJ, et al. Smoking is associated with shortened airway cilia. PLoS ONE 2009; 4: e8157.

39 Simet SM, Sisson JH, Pavlik JA, et al. Long-term cigarette smoke exposure in a mouse model of ciliated epithelial cell function. Am J Respir Cell Mol Biol 2010; 43: 635-640.

40 Hogg JC, Chu FS, Tan WC, et al. Survival after lung volume reduction in chronic obstructive pulmonary disease: insights from small airway pathology. Am J Respir Crit Care Med 2007; 176: 454-459.

41 McDonough JE, Yuan R, Suzuki M, et al. Small-airway obstruction and emphysema in chronic obstructive pulmonary disease. $N$ Engl J Med 2011; 365: 1567-1575.

42 Bell AS, Lawrence PJ, Singh D, et al. Feasibility and challenges of using multiple breath washout in COPD Int J Chron Obstruct Pulmon Dis 2018; 13: 2113-2119. 